\title{
Gallbladder cancer: epidemiology and outcome
}

This article was published in the following Dove Press journal:

Clinical Epidemiology

7 March 2014

Number of times this article has been viewed

\section{Rajveer Hundal \\ Eldon A Shaffer \\ Division of Gastroenterology, Department of Medicine, Faculty of Medicine, University of Calgary, Calgary, Alberta, Canada}

Correspondence: Eldon A Shaffer Division of Gastroenterology (TRW Building), Faculty of Medicine, University of Calgary, 3280 Hospital Drive NW, Calgary, AB, T2N 4Z6, Canada

Tel + I 4032208457

Fax +l 4035925090

Email shaffer@ucalgary.ca
Abstract: Gallbladder cancer, though generally considered rare, is the most common malignancy of the biliary tract, accounting for $80 \%-95 \%$ of biliary tract cancers. An early diagnosis is essential as this malignancy progresses silently with a late diagnosis, often proving fatal. Its carcinogenesis follows a progression through a metaplasia-dysplasia-carcinoma sequence. This comprehensive review focuses on and explores the risks, management, and outcomes for primary gallbladder carcinoma. Epidemiological studies have identified striking geographic and ethnic disparities - inordinately high occurrence in American Indians, elevated in Southeast Asia, yet quite low elsewhere in the Americas and the world. Age, female sex, congenital biliary tract anomalies, and a genetic predisposition represent important risk factors that are immutable. Environmental triggers play a critical role in eliciting cancer developing in the gallbladder, best exemplified by cholelithiasis and chronic inflammation from biliary tract and parasitic infections. Mortality rates closely follow incidence; those countries with the highest prevalence of gallstones experience the greatest mortality from gallbladder cancer. Vague symptoms often delay the diagnosis of gallbladder cancer, contributing to its overall progression and poor outcome. Surgery represents the only potential for cure. Some individuals are fortunate to be incidentally found to have gallbladder cancer at the time of cholecystectomy being performed for cholelithiasis. Such an early diagnosis is imperative as a late presentation connotes advanced staging, nodal involvement, and possible recurrence following attempted resection. Overall mean survival is a mere 6 months, while 5-year survival rate is only 5\%. The dismal prognosis, in part, relates to the gallbladder lacking a serosal layer adjacent to the liver, enabling hepatic invasion and metastatic progression. Improved imaging modalities are helping to diagnose patients at an earlier stage. The last decade has witnessed improved outcomes as aggressive surgical management and preoperative adjuvant therapy has helped prolong survival in patients with gallbladder cancer. In the future, the development of potential diagnostic markers for disease will yield screening opportunities for those at risk either with ethnic susceptibility or known anatomic anomalies of the biliary tract. Meanwhile, clarification of the value of prophylactic cholecystectomy should provide an opportunity for secondary prevention. Primary prevention will arrive once the predictive biomarkers and environmental risk factors are more clearly identified.

Keywords: gallstones, cholelithiasis, incidence, cholecystectomy, gallbladder polyp, anomalous junction of the pancreaticobiliary duct, primary sclerosing cholangitis

\section{Introduction}

Gallbladder cancer is the most common malignancy of the biliary tract, representing $80 \%-95 \%$ of biliary tract cancers worldwide, according to autopsy studies. ${ }^{1}$ It ranks sixth among gastrointestinal cancers. However, the global rates for gallbladder cancer exhibit striking variability, reaching epidemic levels for some regions 
and ethnicities. The basis for this variance likely resides in differences in environmental exposure and intrinsic genetic predisposition to carcinogenesis. These risk factors vary geographically and among ethnic groups. In most instances, gallbladder cancer develops over 5 to 15 years, when metaplasia progresses to dysplasia, carcinoma in situ, and then, invasive cancer. ${ }^{1}$ Progression is frequently rapid and silent, portending a dismal prognosis. A satisfactory outcome depends on an early diagnosis and surgical resection. Despite this potential for cure, less than $10 \%$ of patients have tumors that are resectable at the time of surgery, while nearly $50 \%$ have lymph node metastasis. ${ }^{2}$ Even with surgery, most progress to metastatic disease, highlighting the importance of improving adjuvant therapies. ${ }^{3}$

\section{Mortality}

Gallbladder cancer has an abysmal prognosis. Silent in its infancy, this malignancy remains asymptomatic until aggressive disease has progressed to an advanced and noncurative stage. In fact, the overall mean survival rate for patients with gallbladder cancer is 6 months, with a 5-year survival rate of $5 \% .{ }^{4}$ Such a high mortality rate is, in part, due to aberrant anatomical features: the gallbladder wall lacks a serosal layer adjacent to the liver. Its perimuscular connective tissue is contiguous with hepatic connective tissue, enabling invasion of the liver and metastatic progression.

From an epidemiological perspective, the mortality rates closely follow incidence: those countries with the highest incidence experience the highest mortality. Worldwide, the burden peaks in the Mapuche Indians of Chile (35 per 100,000 each year), closely followed by Hispanics and North American Indians. A lack of access to health care in some regions of the world unquestionably contributes. For instance, the frequency of cholecystectomy for gallbladder disease is likely a mitigating factor. ${ }^{5}$ Mortality is declining in some countries, like the USA, Canada, Australia, and parts of Europe (the UK and Hungary), but increasing in others, including Chile and Japan. ${ }^{1}$

\section{Risk factors}

The available epidemiological studies for gallbladder cancer have been generally limited by small sample sizes, variations in their clinical and pathological criteria, and the challenge in assessing exposure to any presumed risk factor. However, the identification of risk factors is critical, providing insight into the pathogenetic mechanism that drives geographic and ethnic variance, and yielding strategies for prevention and treatment.

\section{Age}

Gallbladder cancer rates tend to increase with advancing age. The median age was 67 years in a Memorial Sloan-Kettering report of 435 gallbladder cancer patients. ${ }^{3}$ US data from 2010 reveals that age-adjusted incidence rates (per 100,000) in 2010 rose from $0.16 / 100,000$ (for those 20-49 years) to $1.47 / 100,000$ (for those 50-64 years), to 4.91/100,000 (65-74 years), and to $8.69 / 100,000$ for individuals over the age of 75 years. This corresponded with mortality rates (per 100,000), which increased from $0.08 / 100,000$ (for those 20-49 years) to $0.77 / 100,000$ (50-64 years) and to $2.68 / 100,000$ (65-74 years). The highest mortality rate was $5.05 / 100,000$, for individuals over the age of $75 .^{6}$

\section{Sex}

Sex differences demonstrate a marked predominance of women over men worldwide, especially in northern India, Pakistan, and in American Indian females. ${ }^{7}$ Women are affected two to six times more often than men. ${ }^{8}$ The importance of female sex hormones is strengthened through gallbladder cancer being associated with a high parity and greater number of pregnancies. ${ }^{7}$ The role of estrogen receptor and progesterone receptor expression in gallbladder cancer is not significantly different between men and women. However, the coexpression of both receptors is increased in females with gallbladder cancer as compared with males, identifying a potential target for treatment. ${ }^{9}$

\section{Geography/ethnicity}

There is a widely variable geographic pattern for gallbladder cancer, unlike other tumors of the extrahepatic biliary tract and the ampulla of Vater. The incidence rates are extraordinarily high in Latin America and Asia, relatively high in some countries in eastern and central Europe (eg, Hungary, Germany, and Poland), yet low in the United States and most western and Mediterranean European countries (eg, UK, France, and Norway). ${ }^{4}$ Gallbladder cancer tends to particularly afflict indigenous populations, according to a vast global cancer registry on five continents (representing 704.4 million people or $11 \%$ of the world population). ${ }^{10}$ Mapuche Indians from Valdivia, Chile, South America exhibit the highest rate of gallbladder cancer: 12.3/100,000 for males and 27.3/100,000 for females. American Indians in New Mexico, USA, follow, with an average annual rate of $8.9 / 100,000$. For these native people, gallbladder cancer mortality rates exceed those for breast $(8.7 / 100,000)$, cervical $(8.0 / 100,000)$, pancreatic $(7.4 / 100,000)$, and ovarian cancers $(7.3 / 100,000) .{ }^{11}$ 
Asia is a high risk continent, where an increased frequency of gallbladder cancer occurs in northern Indian females, Pakistani females, ${ }^{7}$ and Korean males. Ethnic rates can prevail even in different geographic locations. The Korean people have the highest incidence rate (per 100,000) of gallbladder cancer in Asia: 8.1 for males and 5.6 for females. Korean males living in Los Angeles County, California also carry the highest US ethnic incidence rate at 5.9. ${ }^{6}$ Figure 1 summarizes the quite variable global incidence rates for gallbladder cancer.

\section{Gallstones}

Gallstones represent an important risk factor for this malignancy, being present in most ( $85 \%$ ) patients with gallbladder cancer. Further, gallbladder cancer rates correlate well with the prevalence of gallstone disease, ${ }^{12}$ which more commonly affects certain indigenous populations, particularly in North and South America. From a different perspective, however, the overall risk of gallbladder cancer occurring in those with stones is low; fewer than $3 \%$ of individuals with cholelithiasis have gallbladder cancer.

Increased rates for both gallbladder cancer incidence (per 100,000) and gallstone prevalence (\%) occur in Pima Indian females $(21 / 100,000$ cancer incidence and $75.8 \%$ gallstone prevalence),${ }^{13}$ North American Indian females $(7.1 / 100,000$ and $64.1 \%),{ }^{14}$ Chilean Mapuche Indian females $(27.3 / 100,000$ and $49.4 \%),{ }^{15}$ and East Indian females $(22 / 100,000$ and $21.6 \%) .{ }^{16}$ These rates are further summarized in Figure 2. Gallbladder cancer as a consequence of long-standing gallstones is also over-represented among New Zealand Maori, ${ }^{17}$ suggesting an increased prevalence of gallstones in this native population. ${ }^{18}$ Ethnic predilections exist in the USA, where Caucasians carry a higher prevalence of gallstones $(16.6 \%$ of women and $8.6 \%$ of men) compared with Black Americans (13.9\% of women and $5.3 \%$ of men). ${ }^{14,19}$

Gallstone characteristics further influence the frequency at which gallbladder cancer develops. Increasing stone size augments the risk of gallbladder cancer; stones $>3 \mathrm{~cm}$ carry a tenfold increased risk when compared with smaller stones. ${ }^{20,21}$ The stone type may also matter. American Indians and other groups who have a high incidence of carcinoma of the gallbladder also have an inordinately high prevalence of cholesterol gallstone disease. ${ }^{22}$ The basis for this relationship likely resides in gallstones creating local mucosal irritation and chronic inflammation, perhaps aided by the local production of carcinogens, such as secondary bile acids. ${ }^{23}$

In support of this association, an inverse correlation exists between cholecystectomy for cholelithiasis and gallbladder cancer rates, ${ }^{23}$ potentially influenced by poor socioeconomic status for some populations and hence, delayed access to cholecystectomy. Prophylactic cholecystectomy would appear reasonable in these individuals; however, this indication for surgery is not widely endorsed and may in fact,

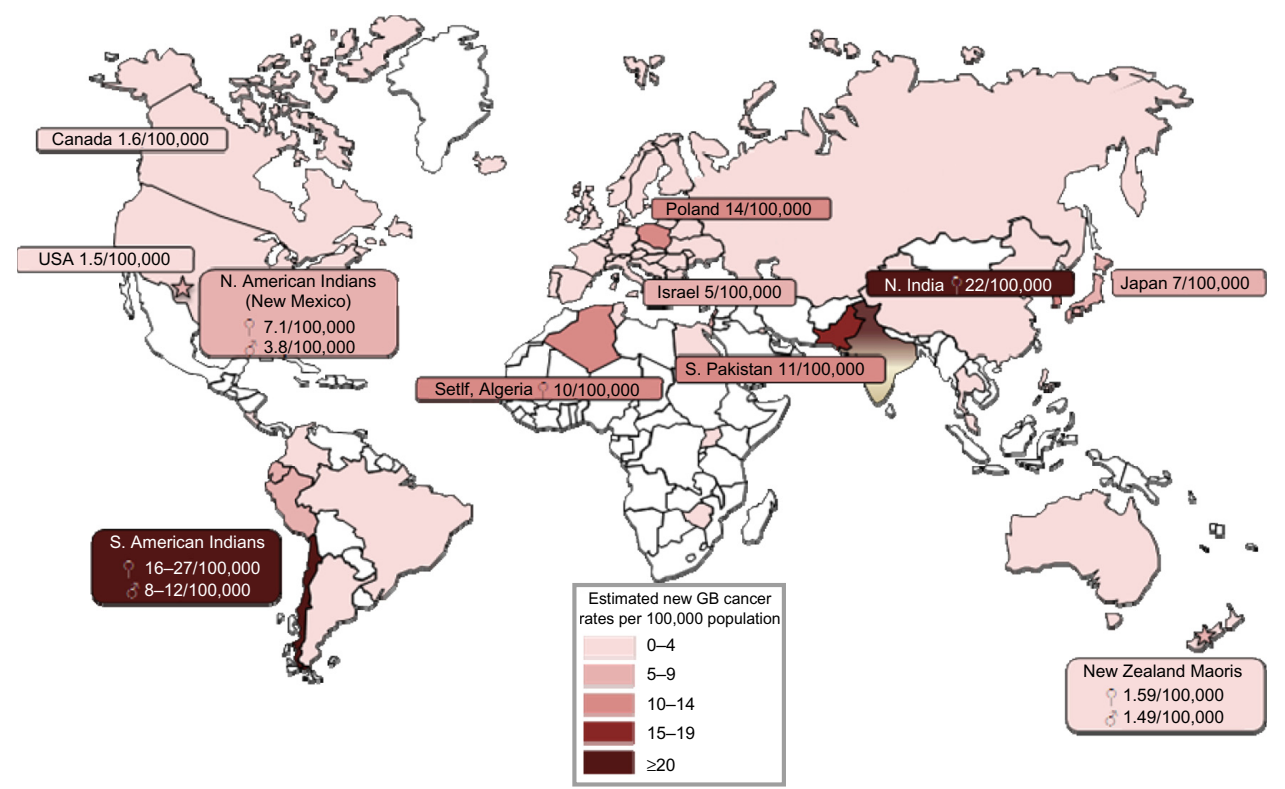

Figure I Gallbladder cancer incidence in the world.

Note: Gallbladder cancer incidence rates are highest among certain ethnicities, particularly South American Indians and East Indian (northern India) females. Statistics derived from Cancer Incidence in Five Continents, Vol IX. 10 This figure is adapted with permission from Stinton LM, Shaffer EA. Epidemiology of Gallbladder Disease: Cholelithiasis and Cancer. Gut Liver. 2012;6(2): 172-187. ${ }^{19}$

Abbreviations: GB, gallbladder; N, North; S, South. 


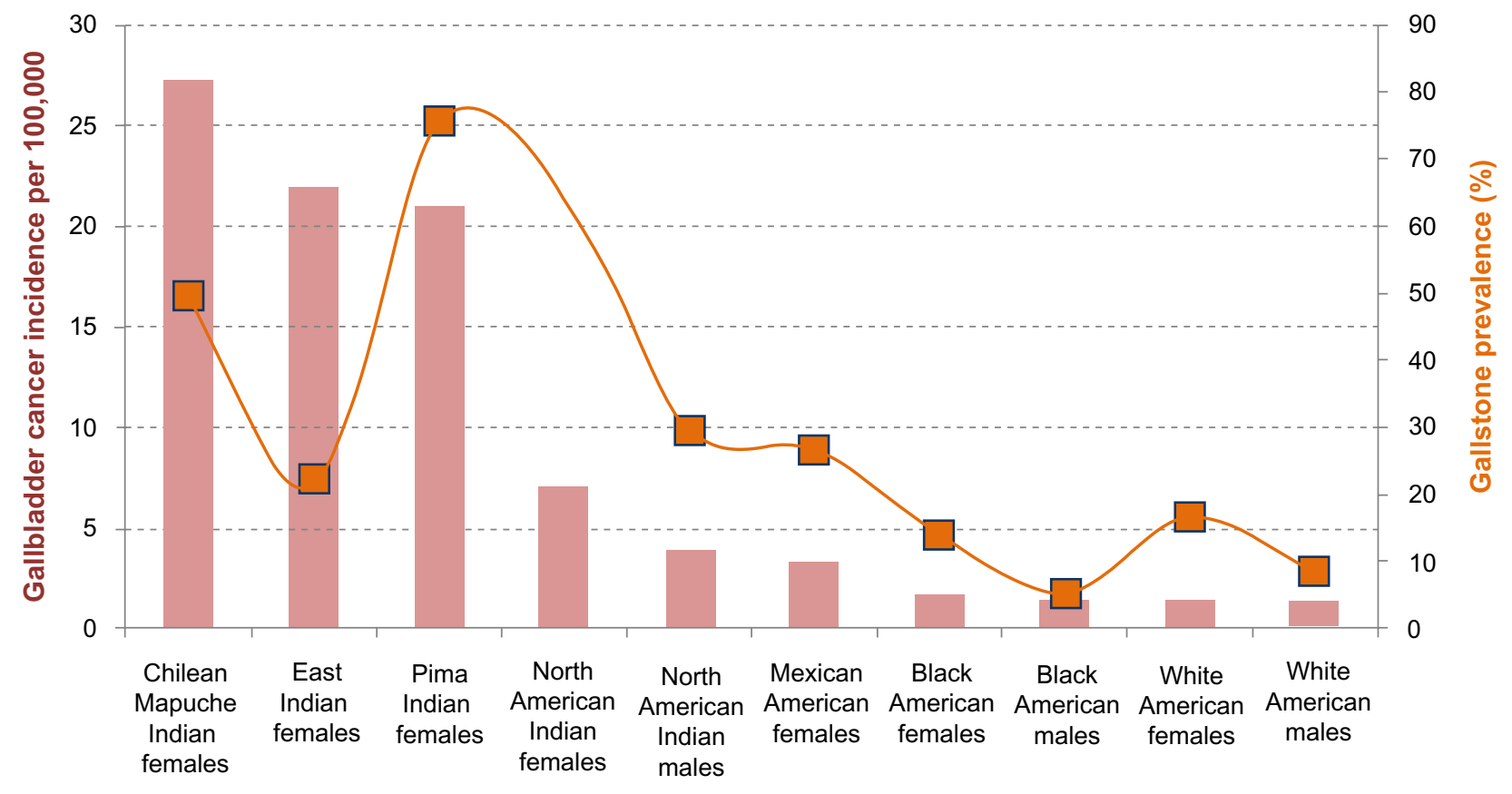

Gallbladder cancer incidence

$\square-\quad$ Gallstone prevalence

Figure 2 Gallbladder cancer incidence and gallstone prevalence in high-risk populations.

Note: Both gallbladder cancer incidence and gallstone prevalence are elevated in certain ethnicities, highlighting gallstones as a major risk factor for gallbladder cancer.

be controversial. The decline in incidence and mortality of gallbladder cancer began decades before the introduction of laparoscopic cholecystectomy and apparently has stabilized in the past decade. No temporal relationship has been found to exist between laparoscopic cholecystectomy rate and the incidence and mortality rates of gallbladder cancer. ${ }^{24}$

\section{Chronic inflammation}

Chronic inflammation is inexorably linked to malignant transformation, being a major factor in carcinogenesis. Recurrent or chronic inflammatory insults are detrimental, causing deoxyribonucleic acid (DNA) damage, provoking repeated tissue proliferative attempts at restoration, releasing cytokines and growth factors, and thus, predisposing cells to oncogenic transformation. Mediators, such as nuclear factor kappa B, reactive oxygen and nitrogen species, inflammatory cytokines, prostaglandins, and specific micro-ribonucleic acids (micro-RNAs) might be oncogenic, acting through changes in cell proliferation, cell death (apoptosis), DNA mutation rates, DNA methylation, and angiogenesis. ${ }^{25}$ Hence, cholelithiasis with its attendant repeated trauma, leading to chronic cholecystitis, might be the mechanism by which cancer develops after many years.

Chronic inflammation can also result in calcium being deposited in the gallbladder wall. When calcium deposits become extensive, the gallbladder acquires a bluish hue and becomes fragile, even brittle - hence the term "porcelain gallbladder." ${ }^{26}$ The frequency of such calcification, although uncommon ( $<1 \%$ of gallbladder specimens), tends to occur in older women in their sixth decade. The porcelain gallbladder is frequently (average $25 \%$, range $12 \%-61 \%$ ) associated with gallbladder cancer, in most but not all reports. ${ }^{27,28}$ In a recent systematic review of 340 patients with gallbladder calcifications, $21 \%$ had gallbladder malignancy. ${ }^{29}$ Only those with stippled calcification are considered premalignant; cases exhibiting transmural calcification are less likely to be associated with carcinoma. ${ }^{27}$ Hence, gallbladders with partial calcification, stippled, or multiple punctate calcifications in the glandular spaces of the mucosa should be removed prophylactically. ${ }^{20}$

\section{Infections}

Chronic bacterial cholangitis poses a clear risk for biliary tract malignancy. The organisms that have been most implicated are Salmonella (eg, S. typhi and S. paratyphi) and Helicobacter (eg, H. bilis) spp... ${ }^{30,31}$ Some 6\% of typhoid carriers develop gallbladder cancer, a 12-fold risk increase. Bacterial colonization may effect malignant transformation, through the degradation of bile constituents (ie, bacterial hydrolysis of primary bile acids forming carcinogens and/ or the action of $\beta$-glucuronides). Malignant transformation 
is further implicated via chronic inflammation itself, and/or alterations of tumor suppressor genes (such as tumor protein 53 [p53]) or proto-oncogenes (such as mutations of Kirsten ras oncogene homolog [K-ras]). ${ }^{25,32}$

Other chronic infestations with parasites, like Clonorchis and Opisthorchis, can induce chronic inflammation and biliary stones but have not been evaluated as to the risk for developing gallbladder cancer.

\section{Primary sclerosing cholangitis}

Primary sclerosing cholangitis (PSC) is a chronic fibroinflammatory syndrome linking chronic inflammation to carcinogenesis. ${ }^{33}$ There is an increased frequency of gallbladder mass lesions in patients with PSC; the basis presumably relates to the ongoing inflammation, facilitating a metaplasia-dysplasia-carcinoma sequence. ${ }^{34}$ The strong correlation between gallbladder dysplasia/adenocarcinoma and bile duct dysplasia/cholangiocarcinoma supports the concept of a neoplastic "field effect" along the intrahepatic and extrahepatic biliary tract in PSC patients. ${ }^{34}$ Those with PSC therefore should undergo annual gallbladder cancer surveillance, via abdominal ultrasound screening, for masses. ${ }^{35,36}$ Cholecystectomy should be performed for lesions $>0.8 \mathrm{~cm}$.

\section{Exposures}

Various environmental exposures have been hypothesized to contribute to gallbladder cancer. Heavy metals, like nickel and cadmium, have been implicated, although a true association has yet to be determined. ${ }^{37}$ Miners are often exposed to radon, an inhaled gas, which has been associated with cancer of the lung ${ }^{38}$ and gallbladder. ${ }^{39}$ Tobacco consumption is a significant risk factor. ${ }^{40}$ Some drugs, such as methyldopa and isoniazid, have been implicated. Any association between oral contraceptives and gallbladder cancer is unclear. ${ }^{23}$

\section{Obesity}

Obese people (body mass index [BMI] $>30 \mathrm{~kg} / \mathrm{m}^{2}$ ) clearly experience an increased risk of developing gallbladder cancer. ${ }^{19,41}$ For each 5-point increase in BMI, the relative risk of developing gallbladder cancer increases by 1.59 for women and 1.09 for men. ${ }^{42,43}$ Further studies confirm this heightened risk in females (relative risk $[\mathrm{RR}]=1.88 ; 95 \%$ confidence interval [CI]: $1.66-2.13$ ) than males ( $\mathrm{RR}=1.35 ; 95 \% \mathrm{CI}: 1.09-1.68) .{ }^{44}$ Obesity and the metabolic syndrome also pose other health concerns, some of which might predispose to gallbladder cancer. Diabetes, for example, is a risk factor for stone formation. The risk of developing gallbladder cancer in those with diabetes mellitus exists, even in the absence of gallstones. ${ }^{45}$ It is unclear whether the link between diabetes and obesity confounds this apparent association. The RRs for the most important factors are expressed in terms of odds ratio in Table 1.

\section{Gallbladder polyps}

Almost 5\% of adults harbor gallbladder polyps. ${ }^{42,46}$ Most are pseudopolyps, without neoplastic potential, as: cholesterol polyps (cholesterolosis), composed of lipid-laden foamy macrophages ( $~ 60 \%$ of all gallbladder polyps); adenomyosis $(\sim 25 \%)$, representing hyperplastic mucosa; or inflammatory polyps $(\sim 10 \%)$, constituting granulation/fibrotic tissue., ${ }^{7,47}$ There are no identified risk factors, like age, sex or the metabolic syndrome, for gallbladder polyps. In asymptomatic individuals, polyps and stones are not particularly associated. ${ }^{48}$

In terms of neoplastic polyps, benign adenomas constitute $\sim 4 \%$ of all gallbladder polyps. Their size ranges from 0.5 to $2 \mathrm{~cm}$. It is unclear whether or not benign adenomas progress to adenocarcinomas. Any theorized adenoma-carcinoma sequence is unlikely, given the absence of adenomatous remnants in the mucosa adjacent to the adenocarcinoma. There is also no evidence of $K$-ras mutations that might signify a pathway for carcinogenesis. ${ }^{49}$ Features that predict malignancy are: large polyps ( $>10 \mathrm{~mm})$, a solitary or sessile mass, associated gallstones, the patient's age over 50, and most importantly, rapid polyp growth.,19

Gallbladder polyps generally do not cause any symptoms, being identified incidentally on transabdominal ultrasound that is undertaken for upper abdominal pain or other purposes. Benign polyps are frequently $(\sim 60 \%)$ accompanied by gallstones in those being investigated for

Table I Risk factors for gallbladder cancer

\begin{tabular}{|c|c|c|}
\hline Risk factor & $\begin{array}{l}\text { Relative risk/odds } \\
\text { ratio }\end{array}$ & Reference \\
\hline Gallstones & $3.01-23.8$ & $13-17,19$ \\
\hline \multicolumn{3}{|l|}{ Size of gallstones } \\
\hline $2.0-2.9 \mathrm{~cm}$ & 2.4 & 19,21 \\
\hline$>3.0 \mathrm{~cm}$ & $9.2-10.1$ & \\
\hline \multicolumn{3}{|l|}{ Duration of gallstones } \\
\hline$>20$ years & $6.2-12.1(\mathrm{OR})^{*}$ & \\
\hline \multicolumn{3}{|l|}{ BMI } \\
\hline $30.0-34.9$ & Men: I.8; women: 2. I & 39 \\
\hline \multicolumn{3}{|l|}{ Infections } \\
\hline Helicobacter bilis & $2.6-6.5$ & 19 \\
\hline $\begin{array}{l}\text { Chronic typhoid and } \\
\text { paratyphoid carriers }\end{array}$ & $12.7-167$ & 19 \\
\hline
\end{tabular}

Note: *Duration of gallstones is represented as an odds ratio (OR); the range is shown. This table is adapted with permission from Stinton LM, Shaffer EA. Epidemiology of Gallbladder Disease: Cholelithiasis and Cancer. Gut Liver. 2012;6(2):172-187. ${ }^{19}$ 
upper abdominal pain, making clinical distinction difficult as to the origin of symptoms.$^{50}$ Endoscopic ultrasound (EUS) has become an important imaging modality, with its ability to distinguish between a benign versus a malignant polyp. An internal echo pattern with aggregation on EUS signifies a benign cholesterol polyp. ${ }^{2}$

The features of polypoidal masses that indicate malignancy include: large polyps $(>1 \mathrm{~cm}$; one-quarter being malignant); a solitary polyp; a sessile polyp; polyp growth; associated gallstones; and age over $50-60$ years. ${ }^{46}$ Size does matter. Polyps exceeding $10 \mathrm{~mm}$ warrant cholecystectomy; this is usually done as a laparoscopic procedure, unless malignancy is highly suspected. Recent arguments suggest that even lesions $>6 \mathrm{~mm}$ may be a more suitable benchmark for resection. ${ }^{47}$ Gallbladder polyps not resected should be followed by serial ultrasonography at 6- to 12-month intervals as benign polyps do not grow.

\section{Anomalous junction of the pancreaticobiliary duct}

The pancreatic and common bile ducts normally are confluent at the ampulla of Vater. An anomalous junction of the pancreaticobiliary duct is a congenital malformation in which the pancreatic duct drains into the biliary tract outside the duodenal wall. This variance is readily detected on cholangiography, either with endoscopic retrograde cholangiopancreatography (ERCP) or magnetic resonance cholangiopancreatography (MRCP), or through EUS imaging. The anomaly is rare in western countries but more apparent in Asians, particularly those of Japanese origin. ${ }^{49}$ Such a long common channel defeats the gatekeeper function of the sphincter of Oddi, potentially allowing pancreatic secretions to regurgitate into the bile ducts and gallbladder, thus leading to malignant changes in the mucosa. ${ }^{52}$ The association tends to occur in relatively young women, yet is not associated with stones. Roughly $10 \%$ of patients with gallbladder cancer have this junction anomaly; ${ }^{2}$ the gallbladder cancer here usually manifests histologically as a papillary carcinoma. ${ }^{7}$ This subtype of adenocarcinoma has a somewhat decreased risk of invasion and metastasis. Nevertheless, prophylactic cholecystectomy should be considered in those with an anomalous junction of the pancreaticobiliary duct.

\section{Genetics}

Gallbladder cancer ensues from an interaction between an innate genetic predisposition and exposure to environmental risk factors. Genetic factors undoubtedly govern some of the widely variable frequency of gallbladder cancer worldwide. One shared genetic risk is gallstone disease and gallbladder cancer. A family history of gallbladder disease increases the risk of developing gallbladder cancer. ${ }^{53}$ For gallstone disease, the genetic background accounts for $\sim 25 \%$ of the total disease risk. ${ }^{19}$ In turn, the stone might be the major ingredient leading to the development of gallbladder cancer.

The molecular pathogenesis results from an accumulation of mutations, eventually leading to malignancy. The common genetic alterations are in the oncogenes, tumor suppressor genes, microsatellite instability, and methylation of gene promoter areas. ${ }^{54}$ Proposed carcinogenic pathways include: 1) gallstone-mediated inflammation, p53 mutation, and eventual carcinoma; 2) K-ras point mutations contributing to atypical epithelium and eventually carcinoma (the hyperplasia-carcinoma sequence observed in patients with an anomalous junction of the pancreaticobiliary duct); ${ }^{32}$ and 3 ) the potential for neoplastic foci in gallbladder polyps, arising secondarily to K-ras mutations. Tumor growth, as a result of neovascularization, is further promoted via synergy between $p 53$ mutation and upregulated vascular endothelial growth factor. ${ }^{54}$

The exact sequence of molecular alteration underlying gallbladder cancer pathogenesis remains unclear. The genetic determinants in gallbladder carcinogenesis are poorly understood, despite over 1,281 gene mutations having been uncovered to date. ${ }^{55}$ These may be monogenic mutations, in which environmental triggers play only a marginal role, perhaps exemplified in congenital biliary tract anomalies. In other circumstances, polymorphisms slightly increase the risk that is elicited though environmental exposure. Carcinoma of the gallbladder is likely a multistep sequence involving cumulative genetic and epigenetic alterations.

\section{Outcomes}

Survival is critically dependent on an early diagnosis. Most gallbladder cancers are uncovered incidentally at the time of cholecystectomy. Unfortunately, because of a frequent advanced stage at the time of diagnosis, the likelihood of recurrence despite surgical intervention is high. Attempted curative resection often proves futile, and outcomes are rather appalling.

\section{Staging and pathology}

Gallbladder cancer staging, based on the American Joint Committee on Cancer guidelines, ${ }^{56}$ focuses on tumor invasion and the extent of spread. (Figure 3) An early diagnosis can lead to a curative resection (termed " $\mathrm{R} 0$ resection") as tumor invasion is limited to the mucosa or 

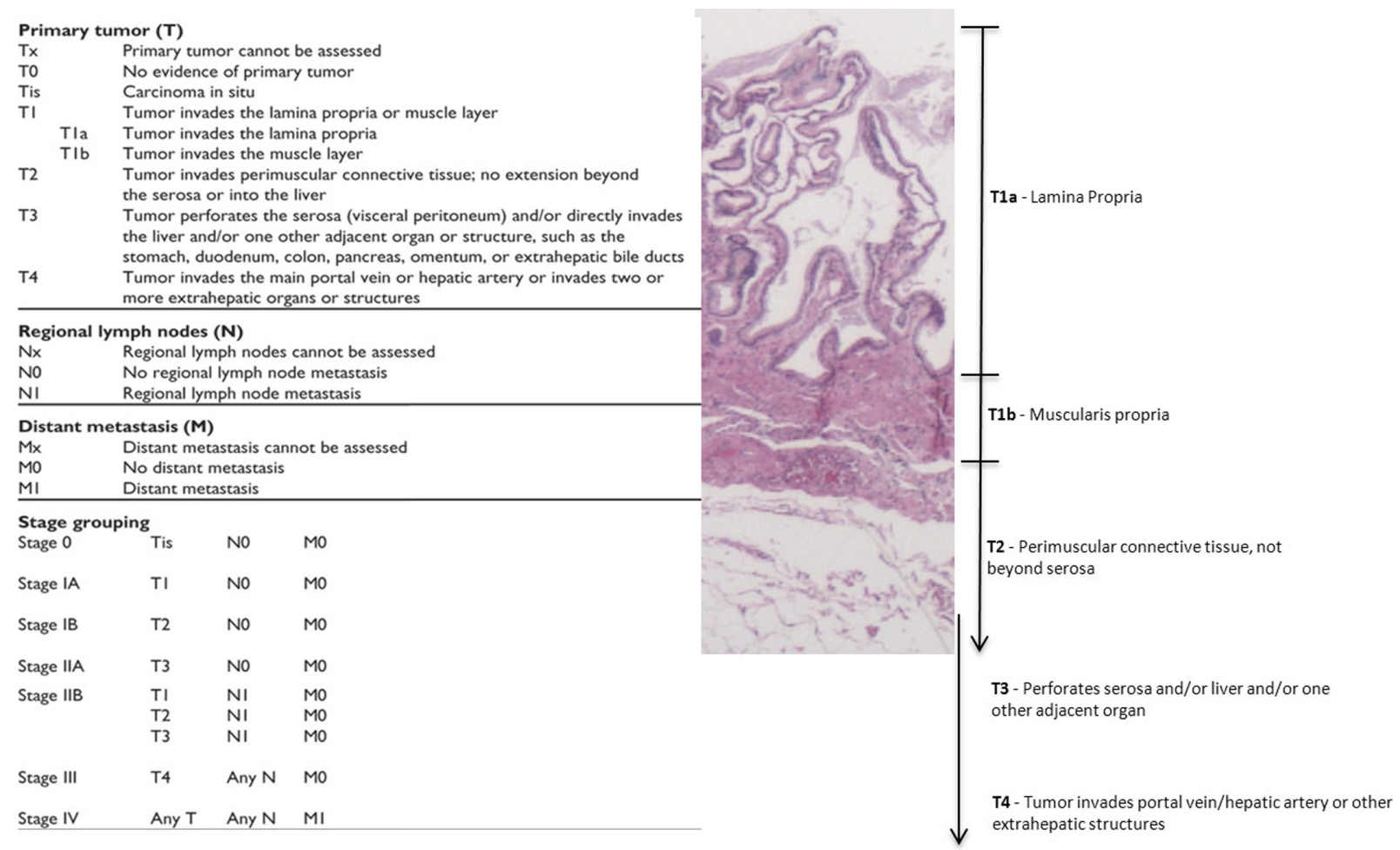

Figure 3 Gallbladder cancer staging and histology.

Notes: Histology courtesy of Dr S Urbanski, Department of Pathology, University of Calgary. Tumor invasion (T) largely drives the staging criteria for gallbladder cancer. Regional lymph nodes $(\mathrm{N})$ and distant metastasis $(\mathrm{M})$ further advance staging and worsen the overall prognosis.

submucosa (ie, Tis $=$ in situ or $\mathrm{T} 1=$ confined to the lamina propria or muscularis). The 5-year survival rates in these patients are over $95 \% .^{57}$

The prognosis worsens when the tumor invades the deeper layers of the gallbladder. In fact, the 5-year survival rates range from $70 \%$ with involvement of the subserosa (T2 = invasion of perimuscular connective tissue), falling to $0 \%$ with the spread to adjacent organs $(\mathrm{T} 3=$ penetration of the serosa). ${ }^{23}$ The metastatic rates also increase with deeper invasion of the gallbladder tumor. Progression from T2 to T4 tumors increases the likelihood of distant metastasis from $16 \%-79 \%$ and the risk of nodal involvement from $33 \%-69 \%{ }^{58,59}$ Tumor invasion may be facilitated by the lack of serosa adjacent to the liver, allowing for hepatic involvement and an automatic T3 designation. T4 tumors signify spread to two or more adjacent organs/structures, warranting palliation in such cases.

Adenocarcinoma is the most frequent histologic type, accounting for $98 \%$ of all gallbladder tumors; two-thirds of these are moderately or poorly differentiated. ${ }^{60}$ The other histopathologic variants include the papillary, mucinous, squamous, and adenosquamous subtypes. The disease stage determines the treatment options. The best outcomes are reserved for patients who qualify for cholecystectomy. In stage I disease, according to American Joint Committee on Cancer criteria, tumor invades the lamina propria or the muscle layer. Stage II is designated by the perforation of the serosa and/or involvement of adjacent organs or structures. T1 to T3 tumor invasion with any nodal involvement is automatically classified as stage II. Both stage I and II are potentially resectable with curative intent. Stage III generally indicates locally unresectable disease, as a consequence of vascular invasion or the involvement of multiple adjacent organs. Stage IV represents nonresectability because of distant metastases. ${ }^{61}$

\section{Diagnosis}

Vague abdominal symptoms often mask a more worrisome diagnosis. Patients with gallbladder cancer may present with a number of nonspecific complaints, like anorexia and weight loss, as a precursor to jaundice. Imaging can detect malignancy. Ultrasound, readily available, might reveal a polypoidal gallbladder mass and perhaps invasion of adjacent structures. Incidental findings include the presence of cholelithiasis and calcification, in the form of the porcelain gallbladder. Wall thickness $(>3 \mathrm{~mm})$ and enhanced vascularity are sonographic features that can also signify potential malignancy. The use of transabdominal, high-resolution ultrasound (HRUS) can differentiate benign adenomyomatosis from gallbladder cancer. ${ }^{62}$ 
EUS is currently the definitive modality for staging gallbladder cancer. The provision of an ultrasound probe in close proximity to the biliary tree allows for precise high-resolution imaging of the gallbladder. EUS also offers sampling via fine needle aspiration. ${ }^{63}$

Computerized tomography (CT) helps identify any extension to lymph nodes, liver involvement, or distant metastases. Dual phase helical CT, often performed preoperatively, determines gallbladder resectability with a high accuracy (up to 93\%); ${ }^{64}$ any vascular involvement precludes this possibility. Standard magnetic resonance imaging (MRI) is generally less valuable. MRCP and three-dimensional magnetic resonance (MR) angiography quite accurately detects vascular invasion, with sensitivity and specificity approaching $100 \%$ and $87 \%$, respectively. ${ }^{65}$

Fluorodeoxyglucose positron emission tomography (FDG-PET) scanning captures the uptake of fluorodeoxyglucose by tumor cells. PET scans are useful in differentiating malignant from benign disease, in preoperative staging, and in detecting postoperative residual disease. ${ }^{54}$ PET scanning may be underutilized. Potentially a more accurate modality for staging in gallbladder cancer, PET scanning would alter management in one-quarter of patients who had undergone more routine staging by US, CT, and MRI. ${ }^{66}$

\section{Surgical management}

Early stage gallbladder cancer can mimic cholecystitis, when presenting with biliary-type abdominal pain that warrants cholecystectomy. Such incidental gallbladder cancers are detected histologically after the fact in $0.3 \%-3 \%$ of laparoscopic cholecystectomies performed for cholelithiasis. In other cases, treatment options usually focus on curative resection, which can be compromised by the extent of tumor invasion. Indeed, primary tumor invasion $(\mathrm{T})$ is the most important subset of the American Joint Committee on Cancer staging criteria; it determines the surgical approach. ${ }^{67}$

Port-site recurrences can follow laparoscopic cholecystectomies in up to $17 \%$ of cases where unsuspected gallbladder cancer is discovered. ${ }^{65}$ Here, accidental bile spillage implants tumor cells at the trocar or incision site, leading to recurrence. Surgical planning for suspected gallbladder cancer thus requires an "open" surgical approach.

As a result, simple cholecystectomy is reserved for $\mathrm{T} 1 \mathrm{a}$ disease and offers a surgical cure. ${ }^{65}$ For T1b lesions, the malignancy extends to the muscle layer, requiring a more radical approach. Patients may require cholecystectomy with wedge resections involving segment $\mathrm{IVb}$ and $\mathrm{V}$ of the liver as well as portal lymphadenectomy. ${ }^{61}$ If the invasion is limited to the mucosa or subserosa, the 5-year survival rate is over $95 \% .{ }^{57} \mathrm{~T} 2$ lesions invade perimuscular connective tissue with no extension beyond the serosa or into the liver. This often requires a more formal resection of segments IVb and $\mathrm{V}^{68} \mathrm{In} \mathrm{T} 3$ disease, the tumor burden may extend to the serosa, liver, and/or adjacent organs/structures. Under these circumstances, resection becomes more radical, including an extended right hepatectomy with possible caudate lobectomy, ${ }^{65}$ regional lymphadenectomy, and extirpation of other affected structures. ${ }^{61}$ Some centers further advocate pancreaticoduodenectomy to improve outcomes.$^{65} \mathrm{~T} 4$ disease is widely disseminated through vascular invasion and/or metastasis. Lesions here are commonly unresectable, and palliation is more appropriate in this setting.

\section{Adjuvant therapies}

Patients often present with advanced disease or locoregional recurrence after surgery. In this setting, alternate regimens become more appropriate. Three classes of chemotherapeutics may be used: gemcitabine, fluoropyrimidines, and platinum compounds. Monotherapy has limited effect. 5-Fluorouracil, when used as a single agent, has been shown to have only a $20 \%$ response rate; gemcitabine had a limited response rate of $36 \%{ }^{54}$ Combination chemotherapy using gemcitabine and cisplatin offers a significant survival advantage for patients with advanced disease. The median progression-free survival in one trial was longer at 8.0 months for patients treated with cisplatin and gemcitabine compared with 5.0 months for those receiving only gemcitabine. ${ }^{69}$

Radiotherapy has proven to be marginally useful in the setting of advanced disease, usually being reserved as adjuvant treatment. In one large study, external beam radiation following curative-intent surgery provided improved survival at 1 year (hazard ratio $0.45 ; P<0.001$ ) but not at 5 years (hazard ratio $1.06 ; P=0.50) .{ }^{70}$ Unfortunately, the data supporting the use of adjuvant or neoadjuvant chemoradiotherapy is largely based on Phase II trials, with no conclusive evidence favoring benefit. ${ }^{61}$

Therapeutic agents, targeting cellular and molecular pathways, can impede tumor growth. ${ }^{71}$ Epidermal growth factor receptor (EGFR) is expressed in $38.5 \%$ of gallbladder cancers. ${ }^{72}$ Targeted therapy against EGFR has demonstrated an antiproliferative effect in vitro ${ }^{72}$ and provides some optimism for a changing treatment paradigm in the future.

\section{Prognosis}

Prognostic factors that may help predict survival after resection include $\mathrm{T}$ staging of the original lesion; extent of nodal involvement; metastasis; and jaundice, which can signify 


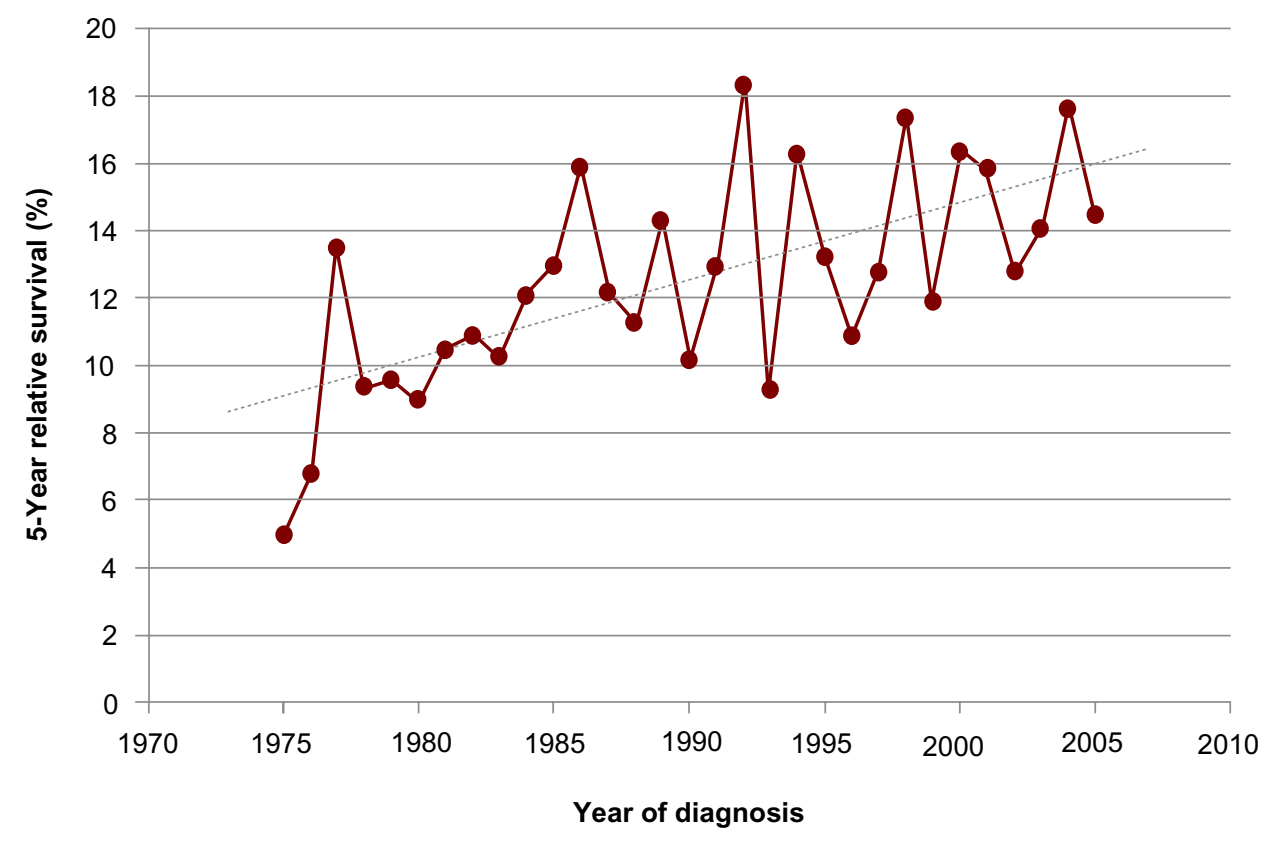

Figure 4 The 5-year relative survival (all ages, all races, both sexes, 1975-2005) for gallbladder cancer in the USA.

Notes: The added trend line highlights the improving survival rates for individuals diagnosed with gallbladder cancer. $\left(y=0.2295 x-444.2 ; R^{2}=0.43366\right)$.

biliary invasion and possible obstruction. ${ }^{61}$ The advent of gallbladder cancer staging has witnessed an improvement in overall 5-year survival rates. The American Joint Committee on Cancer "Cancer Staging Manual" assessed 10,000 patients diagnosed with gallbladder cancer from 1989 to 1996 . The 5 -year survival rates start at $80 \%$ for stage 0 , then progressively fall to $50 \%$ for stage I, $28 \%$ for stage II, $8 \%$ for stage IIIa, $7 \%$ for stage IIIb, $4 \%$ for stage IVa, and finally, $2 \%$ for stage IVb. ${ }^{56}$ Improved 5-year survival rates in the USA are shown in Figure 4.

Unfortunately, the potential for inaccurate initial staging exists. In some individuals, incidental gallbladder cancers found at the time of cholecystectomy can be staged incorrectly. A simple cholecystectomy can leave the cystic plate attached to liver, violating the tumor plane..$^{73}$ Micrometastases may have already occurred, with the potential for further progression as a result of incomplete tumor extirpation. These cases warrant the pathological assessment of, at minimum, six lymph nodes, including partial hepatectomy and portal lymphadenectomy. ${ }^{73}$

The past decade has witnessed better outcomes, especially for patients with node-negative disease. This likely reflects more aggressive surgery and possibly, the use of postoperative adjuvant therapy. Patients may eventually require a second surgery as the chance of residual and additional disease has been reported in over $40 \%$ of cases. ${ }^{74}$ The potential for long-term survival exists in some with node-positive disease. Nonetheless, underestimation of the stage of gallbladder cancer and its notoriously late detection perpetuate an overall dismal prognosis, frequently overriding this opportunity.

\section{Conclusion}

Gallbladder cancer is uncommon in developed countries but has a highly variable prevalence, becoming a common gastrointestinal malignancy in certain populations, most notably American Indians. Originating in a small organ functioning merely for the storage of bile in anticipation of a meal, this distinctive malignancy has disastrous outcomes.

Chronic inflammation, a major risk factor, accompanies cholelithiasis and infection. Diagnosis may come at the time of cholecystectomy for gallstones, although preoperative imaging with transabdominal and endoscopic ultrasound is providing an important advance. Surgery represents the only potential cure. Unfortunately, the usual late presentation means an advanced stage with potential nodal involvement and leads to recurrences despite attempted resection.

Thus, early diagnosis is imperative as surgery can be curative. In fact, cholecystectomy in those at risk, such as American Indians, with even asymptomatic cholelithiasis can prevent the tumor from arising, although such an approach carries inherent risks and cost.

Improved imaging modalities as well as accurate diagnostic markers will potentially help outcomes. Secondary prevention should follow the clarification of the value of prophylactic cholecystectomy in endemic areas and in 
patients at risk. Primary prevention will arrive once high-risk genes and environmental toxins are clearly identified. Recent advances have improved survival rates for individuals diagnosed with gallbladder cancer. Improved outcomes greatly depend on the recognition of the major risk factors, accurate initial staging, and meticulous surgical excision.

\section{Disclosure}

The authors report no conflicts of interest in this work.

\section{References}

1. Lazcano-Ponce EC, Miquel JF, Muñoz N, et al. Epidemiology and molecular pathology of gallbladder cancer. CA: Cancer J Clin. 2001. 2001;51(6):349-364.

2. Sheth S, Bedford A, Chopra S. Primary gallbladder cancer: recognition of risk factors and the role of prophylactic cholecystectomy. Am J Gastroenterol. 2000;95(6):1402-1410.

3. Duffy A, Capanu M, Abou-Alfa GK, et al. Gallbladder cancer (GBC): 10-year experience at Memorial Sloan-Kettering Cancer Centre (MSKCC). J Surg Oncol. 2008;98(7):485-489.

4. Levy AD, Murakata LA, Rohrmann CA Jr. Gallbladder carcinoma: radiologic-pathologic correlation. Radiographics. 2001;21(2):295-314; questionnaire, 549-555.

5. Wistuba II, Gazdar AF. Gallbladder cancer: lessons from a rare tumour. Nat Rev Cancer. 2004;4(9):695-706.

6. Surveillance, Epidemiology and End-Results Program (SEER). The Four Most Common Cancers for Different Ethnic Populations 2013. Bethesda, MD: National Cancer Institute; 2013.

7. Randi G, Franceschi S, La Vecchia C. Gallbladder cancer worldwide: geographical distribution and risk factors. Int J Cancer. 2006;118(7): 1591-1602.

8. Konstantinidis IT, Deshpande V, Genevay M, et al. Trends in presentation and survival for gallbladder cancer during a period of more than 4 decades: a single-institution experience. Arch Surg. 2009;144(5): $441-447$.

9. Gupta P, Agarwal A, Gupta V, Singh PK, Pantola C, Amit S. Expression and clinicopathological significance of estrogen and progesterone receptors in gallbladder cancer. Gastrointest Cancer Res. 2012;5(2): 41-47.

10. Curado MP, Edwards B, Shin HR, et al, editors. Cancer Incidence in Five Continents, Vol IX. Lyon: International Agency for Research on Cancer; 2007.

11. Surveillance, Epidemiology and End-Results Program (SEER). The Four Most Common Cancers for Different Ethnic Populations 2013. Bethesda, MD: National Cancer Institute; 2013.

12. Zatonski WA, Lowenfels AB, Boyle P, et al. Epidemiologic aspects of gallbladder cancer: a case-control study of the SEARCH Program of the International Agency for Research on Cancer. J Natl Cancer Inst. 1997;89(15):1132-1138.

13. Sampliner RE, Bennett PH, Comess LJ, Rose FA, Burch TA. Gallbladder disease in Pima Indians. Demonstration of high prevalence and early onset by cholecystography. N Engl J Med. 1970;283(25): 1358-1364.

14. Everhart JE, Yeh F, Lee ET, et al. Prevalence of gallbladder disease in American Indian populations: findings from the Strong Heart Study. Hepatology. 2002;35(6):1507-1512.

15. Miquel JF, Covarrubias C, Villaroel L, et al. Genetic epidemiology of cholesterol cholelithiasis among Chilean Hispanics, Amerindians, and Maoris. Gastroenterology. 1998;115(4):937-946.

16. Singh V, Trikha B, Nain C, Singh K, Bose S. Epidemiology of gallstone disease in Chandigarh: a community-based study. J Gastroenterol Hepatol. 2001;16(5):560-563.
17. Koea J, Phillips A, Lawes C, Rodgers M, Windsor J, McCall J. Gall bladder cancer, extrahepatic bile duct cancer and ampullary carcinoma in New Zealand: Demographics, pathology and survival. ANZ J Surg. 2002;72(12):857-861.

18. Stringer MD, Fraser S, Gordon KC, Sharples K, Windsor JA. Gallstones in New Zealand: composition, risk factors and ethnic differences. $A N Z$ J Surg. 2013;83(7-8):575-580.

19. Stinton LM, Shaffer EA. Epidemiology of gallbladder disease: cholelithiasis and cancer. Gut Liver. 2012;6(2):172-187.

20. Lowenfels AB, Walker AM, Althaus DP, Townsend G, Domellöf L. Gallstone growth, size, and risk of gallbladder cancer: an interracial study. Int J Epidemiol. 1989;18(1):50-54.

21. Diehl AK. Gallstone size and the risk of gallbladder cancer. JAMA. 1983;250(17):2323-2326.

22. Shaffer EA. Epidemiology of gallbladder stone disease. Best Pract Res Clin Gastroenterol. 2006;20(6):981-996.

23. Shaffer EA. Gallbladder cancer: the basics. Gastroenterol Hepatol (NY). 2008;4(10):737-741.

24. Le MD, Henson D, Young H, Albores-Saavedra J. Is gallbladder cancer decreasing in view of increasing laparoscopic cholecystectomy? Ann Hepatol. 2011;10(3):306-314.

25. Rashid A, Ueki T, Gao YT, et al. K-ras mutation, p53 overexpression, and microsatellite instability in biliary tract cancers: a population-based study in China. Clin Cancer Res. 2002;8(10):3156-3163.

26. Berk RN, Armbuster TG, Saltzstein SL. Carcinoma in the porcelain gallbladder. Radiology. 1973;106(1):29-31.

27. Stephen AE, Berger DL. Carcinoma in the porcelain gallbladder: a relationship revisited. Surgery. 2001;129(6):699-703.

28. Cunningham SC, Alexander HR. Porcelain gallbladder and cancer: ethnicity explains a discrepant literature? Am J Med. 2007;120(4): e17-e18.

29. Schnelldorfer T. Porcelain gallbladder: a benign process or concern for malignancy? J Gastrointest Surg. 2013;17(6):1161-1168.

30. Kumar S. Infection as a risk factor for gallbladder cancer. J. Surg. Oncol. 2006;93(8):633-639.

31. Gonzalez-Escobedo G, Marshall JM. Chronic and acute infection of the gall bladder by Salmonella Typhi: understanding the carrier state. Nature Reviews: Microbiology. January 2011;9(1):9-14.

32. Saetta AA. K-ras, p53 Mutations, and Microsatellite Instability (MSI) in Gallbladder Cancer. J. Surg. Oncol. June 15, 2006;93(8):644-649.

33. Razumilava N, Gores GJ, Lindor KD. Cancer surveillance in patients with primary sclerosing cholangitis. Hepatology. October 28, 2011;54(5):1842-1852.

34. Lewis JT, Talwalkar JA, Rosen CB, Smyrk TC. Prevalence and Risk Factors for Gallbladder Neoplasia in Patients With Primary Sclerosing Cholangitis: Evidence for a Metaplasia-Dysplasia-Carcinoma Sequence. American Journal of Surgical Pathology. June 1, 2007;31(6): 907-913.

35. Chapman R, Fevery J, Kalloo A, Nagorney DM, Boberg KM, Shneider B, et al. Diagnosis and management of primary sclerosing cholangitis. Hepatology. February 2010;51(2):660-678.

36. European Association for the Stud. EASL Clinical Practice Guidelines: Management of cholestatic liver diseases. Journal of Hepatology. August 2009;51(2):237-267.

37. Pandey M. Environmental pollutants in gallbladder carcinogenesis. J. Surg. Oncol. 2006;93(8):640-643.

38. Lubin JH, Boice JD, Edling C, Hornung RW, Howe GR, Kunz E, et al. Lung Cancer in Radon-Exposed Miners and Estimation of Risk From Indoor Exposure. Journal of the National Cancer Institute. June 7, 1995;87(11):817-827.

39. Darby SC, Whitley E, Howe GR, Hutchings SJ, Kusiak RA, Lubin JH, et al., editors. Radon and Cancers Other Than Lung Cancer in Underground Miners: a Collaborative Analysis of 11 Studies. Journal of the Cancer Institute. March 1, 1995;87(5):378-384.

40. Jain K, Sreenivas V, Velpandian T, Kapil U, Garg PK. Risk factors for gallbladder cancer: A case-control study. Int. J. Cancer. September 21, 2012;132(7):1660-1666. 
41. Calle EE, Rodriguez C, Walker-Thurmond K, Thun MJ. Overweight, Obesity, and Mortlity from Cancer in a Prospectively Studied Cohort of U.S. Adults. The New England Journal of Medicine. April 24, 2003;348(17): $1625-1638$.

42. Hariharan D, Saied A, Kocher HM. Analysis of mortality rates for gallbladder cancer across the world. MHPB. 2008;10(5):327-331.

43. Wolin KY, Carson K, Colditz GA. Obesity and Cancer. The Oncologist. June 24, 2010;15(6):556-565.

44. Larsson SC, Wolk A. Obesity and the risk of gallbladder cancer: a meta-analysis. British Journal of Cancer. May 7, 2007;96(9): 1457-1461.

45. Lai HC, Chang SN, Lin CC, Chen CC, Chou JW, Peng CY, et al. Does diabetes mellitus with or without gallstones increase the risk of gallbladder cancer? Results from a population-based cohort study. $J$ Gastroenterol. July 2013;48(7):856-865.

46. Myers RP, Shaffer EA. Gallbladder polyps: Epidemiology, natural history and management. Canadian Journal of Gastroenterology. March 2002;16(3):187-194.

47. Gallahan WC, Conway JD. Diagnosis and Management of Gallbladder Polyps. Gastroenterology \& Hepatology. June 2010;39(2):359-367.

48. Jorgensen T, Jensen KH. Polyps in the gallbladder. A prevalence study. Scandinavian Journal of Gastroenterology; March 1990;25(3):281-286

49. Roa I, de Aretxabala X, Morgan R, Molina R, Araya JC, Roa J, et al Clinicopathological features of gallbladder polyps and adenomas. Revista Medica de Chile; June 2004;132(6):673-679.

50. Terzi C, Sokmen S, Seckin S, Albayrak L, Ugurlu M. Polypoid Lesions of the Gallbladder: Report of 100 cases with special reference to operative indications. Surgery. June 2000;127(6):622-627.

51. Nuzzo G, Clemente G, Cadeddu F, Ardito F, Ricci R, Vecchio FM Papillary carcinoma of the gallbladder and anomalous pancreaticobiliary junction. Report of three cases and review of the literature. Hepatogastroenterology; July-August 2005;52(64):1034-1038.

52. Nomura T, Shirai Y, Sandoh N, Nagakura S, Hatakeyama K. Cholangiographic criteria for anomalous union of the pancreatic and biliary ducts. Gastrointestinal Endoscopy. February 2002;55(2):204-208.

53. Dutta U, Nagi B, Garg PK, Sinha SK, Singh K, Tandon RK. Patients with gallstones develop gallbladder cancer at an earlier age. European Journal of Cancer Prevention. August 2005;14(4):381-385.

54. Dutta U. Gallbladder cancer: Can newer insights improve the outcome? Journal of Gastroenterology and Hepatology. March 22, 2012;27(4):642-653.

55. Itol T, Watanabe H, Ajioka Y, Oohashl Y, Takei K, Nishikura K, et al. APC, K-ras codon 12 mutations and p 53 gene expression in carcinoma and adenoma of the gall-bladder suggest two genetic pathways in gall-bladder carcinogenesis. Pathology International. May 1996;46(5):333-340.

56. Edge SB, Byrd DR, Compton CC, Fritz AG, Greene FL, Trotti A, editors. AJCC Cancer Staging Manual 2010 Springer.

57. Ouchi K, Mikuni J. Laparoscopic cholecystectomy for gallbladder carcinoma: results of a Japanese survey of 498 patients. Journal of Hepatobiliary and Pancreatic Surgery. 2002;9(2):256-260.
58. Boutros C, Gary M, Baldwin K, Somasundar P. Gallbladder cancer: Past, present and an uncertain future. Surg Oncol. 2012;21(4):e183-e191.

59. Gallbladder Cancer: Comparison of Patients Presenting Initially for Definitive Operation With Those Presenting After Prior Noncurative Intervention. Ann Surg. 2000;232(4):557-569.

60. Goldin RD, Roa JC. Gallbladder cancer: a morphological and molecular update. Histopathology. 2009;55(2):218-229.

61. Jayaraman S, Jarnagin WR. Management of Gallbladder Cancer. Gastroenterol Clin North Am. 2010;39(2):331-342.

62. Joo I, Lee JY, Kim JH, Kim SJ, Kim MA, Han JK, Choi BI. Differentiation of adenomyomatosis of the gallbladder from early-stage, wallthickening-type gallbladder cancer using high-resolution ultrasound. Eur Radiol. 2012;23(3):730-8.

63. Kim HJ, Lee SK, Jang JW, et al. Diagnostic role of endoscopic ultrasonography-guided fine needle aspiration of gallbladder lesions. Hepatogastroenterology. 2012;59(118):1691-1695.

64. Kumaran V, Gulati MS, Paul SB, Kumar Pande G, Sahni P, Chattopadhyay TK. The role of dual-phase helical CTin assessing resectability of carcinoma of the gallbladder. Eur Radiol. 2002;12(8):1993-1999.

65. Reid KM, Ramos-De la Medina A, Donohue JH. Diagnosis and surgical management of gallbladder cancer: a review. J Gastrointest Surg. 2007;11(5):671-681.

66. Corvera CU, Blumgart LH, Akhurst T, DeMatteo RP, D'Angelica M, Fong Y, Jarnagin WR. 18F-fluorodeoxyglucose positron emission tomography influences management decisions in patients with biliary cancer. J Am Coll Surg. 2008;206(1):57-65.

67. Pilgrim CHC, UsatoffV, Evans P. Consideration of anatomical structures relevant to the surgical strategy for managing gallbladder carcinoma Eur J Surg Oncol. 2009;35(11):1131-1136.

68. Pilgrim C, Usatoff V, Evans PM. A review of the surgical strategies for the management of gallbladder carcinoma based on T stage and growth type of the tumour. Eur J Surg Oncol. 2009;35(9):903-907.

69. Valle J, Wasan H, Palmer DH, et al. Cisplatin plus gemcitabine versus gemcitabine for biliary tract cancer. $N$ Engl $J$ Med. 2010;362(14):1273-1281.

70. Hyder O, Dodson RM, Sachs T, Weiss M, Mayo SC, Choti MA, et al. Impact of adjuvant external beam radiotherapy on survival in surgically resected gallbladder adenocarcinoma: A propensity score-matched Surveillance, Epidemiology, and End Results analysis. Surgery. 2013. pili: S0039-6060(13)00288-2.

71. Aaronson S. Growth Factors and Cancer. Science. 1991;254(5035):1146-1153.

72. Pignochino Y, Sarotto I, Peraldo-Neia C, Penachioni JY, Cavolloni G, Migliardi G, et al. Targeting EGFR/HER2 pathways enhances the antiproliferative effect of gemcitabine in biliarytract and gallbladder carcinomas. BMC Cancer. 2010;10:631

73. Ito $\mathrm{H}$, Ito $\mathrm{K}, \mathrm{D}^{\prime}$ Angelica $\mathrm{M}$, et al. Accurate staging for gallbladder cancer: implications for surgical therapy and pathological assessment. Ann Surg. 2011;254(2):320-325.

74. Pawlik TM, Gleisner AL, Vigano L, et al. Incidence of Finding Residual Disease for Incidental Gallbladder Carcinoma: Implications for Re-resection. J Gastrointest Surg. 2007;11(11):1478-86; discussion 1486-7.
Clinical Epidemiology

\section{Publish your work in this journal}

Clinical Epidemiology is an international, peer-reviewed, open access journal focusing on disease and drug epidemiology, identification of risk factors and screening procedures to develop optimal preventative initiatives and programs. Specific topics include: diagnosis, prognosis, treatment, screening, prevention, risk factor modification, systematic

\section{Dovepress}

reviews, risk \& safety of medical interventions, epidemiology \& biostatical methods, evaluation of guidelines, translational medicine, health policies \& economic evaluations. The manuscript management system is completely online and includes a very quick and fair peer-review system, which is all easy to use. 